\title{
DYNAMIC MODELING AND ANALYSIS OF HELICAL GEAR-SHAFT-BEARING COUPLED SYSTEM
}

\author{
Huan Bai, Chaosheng Song, Caichao Zhu \\ The State Key Laboratory of Mechanical Transmissions, Chongqing University, Chongqing, China \\ e-mail: chaoshengsong@hotmail.com \\ YAWEN WANG \\ University of Texas at Arlington, Department of Mechanical and Aerospace Engineering, Texas, USA \\ ZHUXIANG OU \\ The State Key Laboratory of Mechanical Transmissions, Chongqing University, Chongqing, China
}

\begin{abstract}
Considering bearing clearance, time-varying mesh stiffness, time-varying transmission error and shaft flexibility, a coupled gear-shaft-bearing dynamic model for a helical gear transmission is established. The influences of rotating speed, input torque load and bearing clearance on the dynamics are studied. Results show that the frequency and the magnitude of the peak response increase with the increase of load. As the bearing clearance increases, the amplitude of the dominant mesh frequency is significantly increased. Under lower speed, the clearance has a limited effect on the dynamic mesh force. However, under moderate and high speeds, the main peak response frequency of the dynamic mesh force is decreased as it increases.
\end{abstract}

Keywords: gear-shaft-bearing coupled system, dynamic characteristics, rotating speed, bearing clearance

\section{Introduction}

With the high speed operation requirements of mechanical equipment, the gear transmission system has become a main source of noise. The gear noise problem is a system-level problem. In the previous studies, the bearing is usually considered to be of constant stiffness in the dynamic modeling of the geared rotor system. It is difficult to completely reveal the dynamic interaction between the gear and the bearing sub-systems. Therefore, this paper aims at studying the coupled dynamics of the gear-shaft-bearing system.

For a long time, gear and bearing dynamics are studied separately. Gear dynamics researchers usually take the meshing gear pair as the research object, simplify the bearing by equivalent spring-damper elements, and focus on the impact of gear mesh excitation and other factors. For example, the coupled dynamics model of an electric vehicle reducer was established by considering gear mesh stiffness, transmission error, and tooth side clearance, which can accurately predict the system dynamic response (Yu et al., 2015). The study combined the gear with the shaft to build the overall dynamic model of the system (Lee et al., 2003). The influence of non-linear factors on the system dynamic response was analyzed (Moradi and Salarieh, 2012). The vibration characteristics of the electric vehicle deceleration housing through finite element calculation were extracted, and it was verified through modal experiment (Chen et al., 2013). A finite element elastoplastic contact model was established to study the effect of residual stress of a carburized gear on rolling contact fatigue (Wang et al., 2019). The study developed a dynamic model for a single-stage gear reducer considering time-varying characteristics of gear meshing stiffness, and analyzed the influence of the speed and load on the vibration and noise 
of the reducer (Zhou et al., 2013). The effects of work holding equipment errors on mesh behavior and gear flank geometry of a face-hobbed hypoid gear were studied (Liu et al., 2019). The dynamics of the herringbone gear dynamics model was studied in (Kang and Kahraman, 2016). A nonlinear vibration response caused by manufacturing errors for spur gears, taking into account the impact of clearance and time-varying mesh stiffness, was analyzed in (Bonori and Pellicano, 2007). The dynamic characteristics of a multi-degree-of-freedom gear system considering friction, flank clearance and a time-varying stiffness factor were analyzed by Chen et al. (2011). The study considered gyroscopic moments of the shaft and established the coupled dynamics model of the hypoid gear and the shaft (Wang et al., 2016). The research shows that the combined influence of the gear and the shaft and the gyroscopic behavior have considerable influence on the system dynamic behavior. To quickly extract fault signals of rotating parts, a new method based on the orthogonal matching pursuit and a one-dimensional K-SVD algorithm was proposed (Qin et al., 2019). A gear transmission dynamic model in non-inertial systems was established, and the effects of non-inertial effects on system vibration was studied (Zhang et al., 2019). With the increasing requirements of bearing precision, performance life and reliability in the mechanical industry, the research on bearing dynamic characteristics is particularly important. A 6 degrees-of-freedom (DOF) ball bearing dynamic model considering Hertz contact deformation, elastohydrodynamics, radial clearance, ring waviness and local defects was proposed by Sopanen and Mikkola (2003). Considering the influence of ball-groove contact stiffness and body deformation, a planar multi-body dynamics model for a deep groove ball bearing with clearance was established (Xu and Li, 2012; Xu et al., 2012). The study proposed a bearing dynamic model to investigate dynamic characteristics of the bearing-rotor system considering the internal clearance and waviness of the bearing (Bai and $\mathrm{Xu}, 2006$ ). Considering the influence of the rotor unbalance force on the bearing-rotor system, structural vibration of a high-speed rotor supported by bearings was investigated (Harsha, 2005, 2006). A two-rotor model of an aero-engine with bearing clearance, nonlinear Hertz contact force between rolling elements and rings, and variable flexible vibration was developed (Chen, 2008a,b).

More recently, the research of a gear-rotor-bearing coupled system has received attention by some scholars. The impact of time-varying bearing stiffness on gear system dynamic characteristics was analyzed (Liew and Lim, 2005). The researchers developed a dynamic model of a bevel gear transmission system considering an oil film bearing, and analyzed the nonlinear dynamic behavior under equilibrium and non-equilibrium conditions by a numerical method ( $\mathrm{Li}$, 2008). By using the finite element software ANSYS/LS-DYNA, a coupled dynamic model for a gear transmission system with multi-gaps was developed, and its nonlinear dynamic behaviors were analyzed (Chen et al., 2010). Researchers developed a nonlinear bending-torsional coupled vibration model of the gear-rotor-bearing system considering time-varying meshing stiffness, backlash, bearing clearance and comprehensive transmission error, as well as other nonlinear factors between the gears (Sheng et al., 2014). To summarize, most of the aforementioned studies considered the gear and bearing separately in the modeling. Although lots of research were conducted on the gear transmission system, the coupled interaction between the gear and bearing was rarely considered. In this paper, a single-stage gear transmission system is taken as the research object. A complete coupled gear-shaft-bearing vibration model is developed by the finite element and the lumped parameters methods. Then, the effects of different speeds, load changes and bearing clearances on the system dynamic behavior are investigated.

\section{Dynamic modeling of gear-shaft-bearing coupled system}

The gear transmission system consists of three main components: gear, shaft and bearing. For the modelling, the finite element method and lumped parameters method were used to divide the three types of components into different types of elements. The shaft was divided into a series of 
nodes. Figure 1 shows the overall coupled dynamic model. $x, y, z$ are transverse displacements, and $\theta_{x}, \theta_{y}, \theta_{z}$ are torsional vibration displacements. $\mathbf{F}_{b}, \mathbf{M}_{b}$ are the nonlinear bearing force and torque, respectively. $L$ is length of the shaft element. The subscript number $i(i=1,2, \ldots, 12)$ is the $i$-th node; $s$ is the shaft; $b$ is the bearing; $p$ is the driving gear; $g$ is the driven gear. $c_{m}$ is the mesh damping. $k_{m}(t), e(t)$ are the mesh stiffness and internal error excitation, respectively, which can be represented by

$$
\begin{aligned}
& k_{m}(t)=k_{0}+k_{a} \sin \left(2 \pi f_{m} t+\varphi\right) \\
& e(t)=e_{a} \sin \left(2 \pi f_{m} t+\varphi\right)
\end{aligned}
$$

where $k_{0}, k_{a}$ are the mesh stiffness mean and amplitude, respectively; $e_{a}$ is the transmission error excitation amplitude; $f_{m}$ is the mesh frequency; $\varphi$ is the initial phase angle.

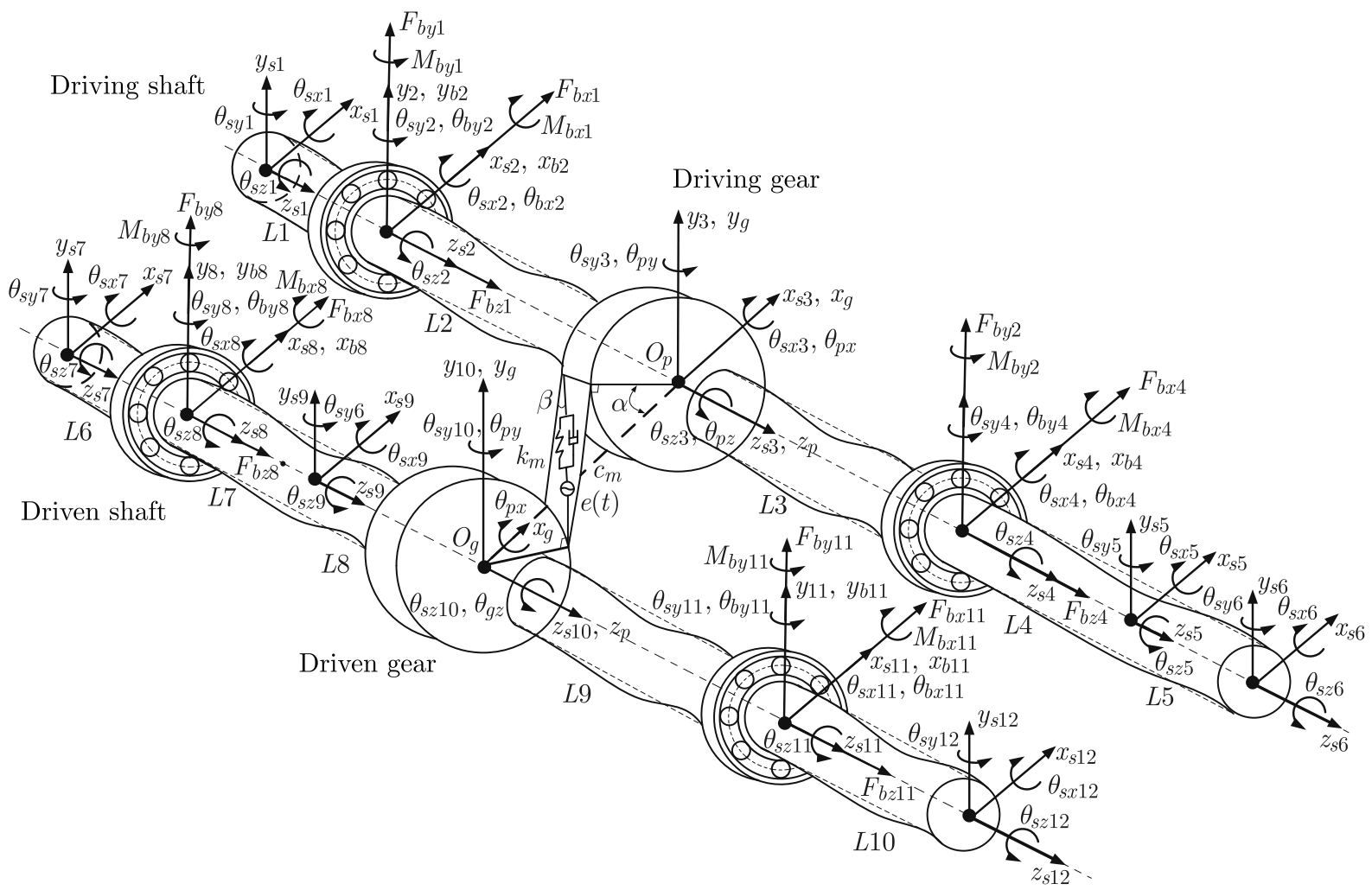

Fig. 1. Dynamic model of the single-stage gear coupled system

By matching the node number of each element, the stiffness matrix, load matrix, damping matrix and mass matrix of each element are assembled into the overall model. Each node has $6 \mathrm{DOF}$ and the overall model has 12 nodes with 72 DOF. Since the bearing only has 5 DOF, it is substituted into a 6 DOF matrix by filling the zero with the remaining degrees of freedom. Then its transition term is put into the load array. The assembly of the stiffness matrix and load array are shown in Figs. 2a and 2b. Also, the mass matrix and the damping matrix can be obtained by the similar assembling method.

So, the systematic dynamic model is shown as follows

$$
\left(\mathbf{M}_{b}+\mathbf{M}_{s}+\mathbf{M}_{g}\right) \ddot{\mathbf{q}}+\left(\mathbf{C}_{b}+\mathbf{C}_{s}+\mathbf{C}_{g}\right) \ddot{\mathbf{q}}+\left[\mathbf{K}_{s}+\mathbf{K}_{g}(t)\right] \mathbf{q}=\mathbf{F}_{g}(t)+\mathbf{F}_{b}(t)+\mathbf{T}
$$

where $\mathbf{q}$ is the displacement array. $\mathbf{M}_{b}, \mathbf{M}_{s}, \mathbf{M}_{g}$ are the bearing mass matrix, shaft mass matrix and gear mass matrix, respectively; $\mathbf{C}_{b}, \mathbf{C}_{s}, \mathbf{C}_{g}$ are the bearing damping matrix, shaft damping matrix and gear damping matrix, respectively; $\mathbf{K}_{s}, \mathbf{K}_{g}(t)$ are the shaft stiffness matrix and gear 
(a)

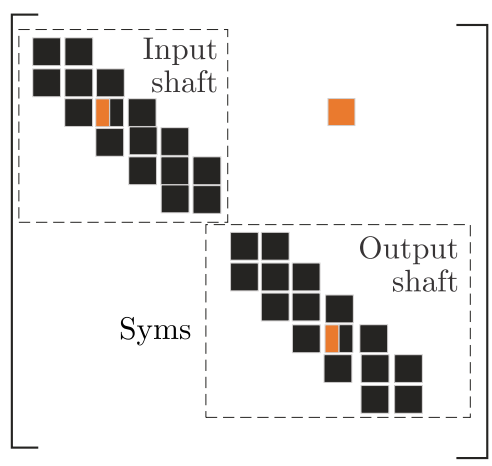

(b)

Shaft unit

Gear meshing unit

Gear and shaft coupling

Fig. 2. (a) Overall stiffness matrix, (b) overall load array

stiffness matrix; $\mathbf{F}_{b}(t)$ is the bearing force column matrix; $\mathbf{F}_{g}(t)$ is the gear internal excitation column matrix; $\mathbf{T}$ is the external torque column matrix.

The shaft stiffness matrix $\mathbf{K}_{s}$ and shaft mass matrix $\mathbf{M}_{s}$ are obtained according to the reference (Stringer, 2008). And the damping matrix $\mathbf{C}_{s}$ is calculated according to Rayleigh formula

$$
\mathbf{C}_{s}=\alpha \mathbf{M}_{s}+\beta \mathbf{K}_{s}
$$

where $\alpha$ and $\beta$ are the mass and stiffness proportionality coefficients, respectively.

The gear stiffness matrix $\mathbf{K}_{g}(t)$ and the internal excitation force of the gear pair $\mathbf{F}_{g}(t)$ are obtained by the following method. by

The total deformation of the gear along the mesh line is denoted by $\delta$ and it can be obtained

$$
\begin{aligned}
\delta= & \left(-x_{p}+x_{g}\right) \sin \alpha \cos \beta_{b}+\left(-y_{p}+y_{g}\right) \cos \alpha \cos \beta_{b}+\left(z_{p}-z_{g}\right) \sin \beta_{b} \\
& +\left(r_{b p} \theta_{p x}+r_{b g} \theta_{g x}\right) \sin \beta_{b} \sin \alpha+\left(r_{b p} \theta_{p y}+r_{b g} \theta_{g y}\right) \sin \beta_{b} \cos \alpha \\
& +\left(r_{b p} \theta_{p z}+r_{b g} \theta_{g z}\right) \cos \beta_{b}
\end{aligned}
$$

The internal excitation force along the gear mesh line $f_{g}(t)$ can be represented by

$$
f_{g}(t)=k_{m}(t) e(t)+c_{m}(t) \dot{e}(t)
$$

Based on the Lagrange energy method, the systematic equations of motion can be obtained as follows

$$
\begin{aligned}
& I_{p x} \ddot{\theta}_{p x}+\left(k_{m}(t) \delta+c_{m} \dot{\delta}\right) r_{b p} \sin \beta_{b} \sin \alpha=-f_{g}(t) r_{b p} \sin \beta_{b} \sin \alpha \\
& I_{p y} \ddot{\theta}_{p y}+\left(k_{m}(t) \delta+c_{m} \dot{\delta}\right) r_{b p} \sin \beta_{b} \cos \alpha=-f_{g}(t) r_{b p} \sin \beta_{b} \cos \alpha \\
& I_{p z} \ddot{\theta}_{p z}+\left(k_{m}(t) \delta+c_{m} \dot{\delta}\right) r_{b p} \cos \beta_{b}=-f_{g}(t) r_{p b} \cos \beta_{b} \\
& m_{p} \ddot{x}_{p}-\left(k_{m}(t) \delta+c_{m} \dot{\delta}\right) \cos \beta_{b} \sin \alpha=f_{g}(t) \cos \beta_{b} \sin \alpha \\
& m_{p} \ddot{y}_{p}-\left(k_{m}(t) \delta+c_{m} \dot{\delta}\right) \cos \beta_{b} \cos \alpha=f_{g}(t) \cos \beta_{b} \cos \alpha \\
& m_{p} \ddot{z}_{p}+\left(k_{m}(t) \delta+c_{m} \dot{\delta}\right) \sin \beta_{b}=-f_{g}(t) \sin \beta_{b} \\
& I_{g x} \ddot{\theta}_{g x}+\left(k_{m}(t) \delta+c_{m} \dot{\delta}\right) r_{b g} \sin \beta_{b} \sin \alpha=-f_{g}(t) r_{b g} \sin \beta_{b} \sin \alpha \\
& I_{g y} \ddot{\theta}_{g y}+\left(k_{m}(t) \delta+c_{m} \dot{\delta}\right) r_{b g} \sin \beta_{b} \cos \alpha=-f_{g}(t) r_{b g} \sin \beta_{b} \cos \alpha \\
& I_{g z} \ddot{\theta}_{g z}+\left(k_{m}(t) \delta+c_{m} \dot{\delta}\right) r_{b g} \cos \beta_{b}=-f_{g}(t) r_{b g} \cos \beta_{b} \\
& m_{g} \ddot{x}_{g}+\left(k_{m}(t) \delta+c_{m} \dot{\delta}\right) \cos \beta_{b} \sin \alpha=-f_{g}(t) \cos \beta_{b} \sin \alpha \\
& m_{g} \ddot{y}_{g}+\left(k_{m}(t) \delta+c_{m} \dot{\delta}\right) \cos \beta_{b} \cos \alpha=-f_{g}(t) \cos \beta_{b} \cos \alpha \\
& m_{g} \ddot{z}_{g}-\left(k_{m}(t) \delta+c_{m} \dot{\delta}\right) \sin \beta_{b}=f_{g}(t) \sin \beta_{b}
\end{aligned}
$$


where $m_{p}, m_{g}, I_{p x}, I_{p y}, I_{p z}, I_{g x}, I_{g y}, I_{g z}$ are masses and moments of inertia of the driving and driven gears; $r_{b p}$ and $r_{b g}$ are the basic radius of the driving and driven gear, respectively; $\beta_{b}$ and $\alpha$ are the base helix and the pressure angles, respectively. So $\mathbf{K}_{g}(t), \mathbf{F}_{g}(t)$ can be obtained by Eqs. (2.6). The nonlinear bearing force $\mathbf{F}_{b}$ is obtained by the following method (Lim and Singh, 1990).

Figure 3 shows the structure diagram of the bearing. $O_{i}, O_{e}$ are the curvature centers of the inner and outer race groove. $A_{i e}$ is the relative distance between $O_{i}$ and $O_{e} .5$ degrees of freedom of the center of the inner race and a fixed outer race are considered.

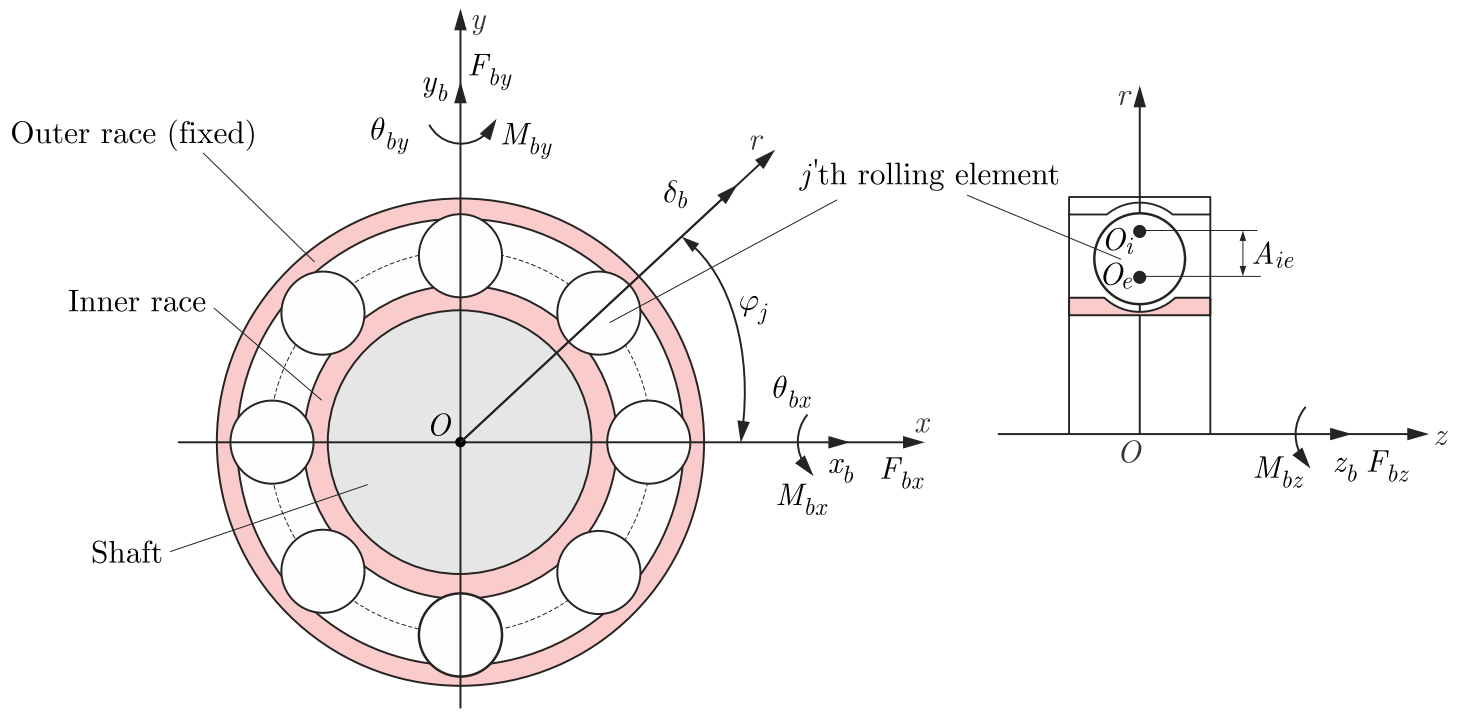

Fig. 3. Rolling bearing structure diagram

Assuming that the bearing has $N$ rolling elements, then in the process of bearing rotation, the azimuth angle of the $j$-th rolling element at any time is (Liew and Lim, 2005)

$$
\varphi_{j}=\frac{2 \pi(j-1)}{N}+\frac{1}{2}\left(1-\frac{r_{b}}{R_{C}} \cos \alpha_{0}\right) w_{i} t \quad j=1,2, \ldots, N
$$

where $\alpha_{0}$ is the unloaded contact angle ( $\alpha_{0}=0$ for deep groove ball bearing), $r_{b}$ is the element radius, $R_{C}$ is the inner race curvature center radius, $w_{i}$ denotes the angular velocity, $t$ denotes time. Then, the bearing passing frequency $V_{C}$ can be calculated by

$$
V_{C}=\frac{1}{2 \pi}\left[\frac{1}{2}\left(1-\frac{r_{b}}{R_{C}} \cos \alpha_{0}\right) w_{i} N\right]
$$

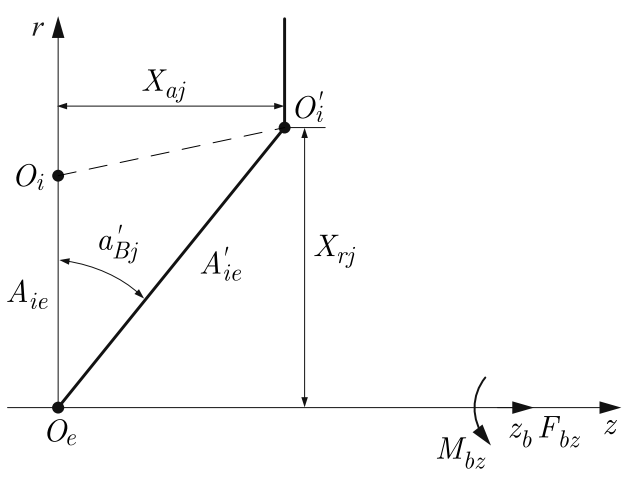

Fig. 4. Displacement-deformation relation 
Bearing deformation mainly means contact deformation between the rolling elements and the inner and outer races. Figure 5 shows the displacement and deformation relationship of the $j$-th rolling element. Since the model assumes that the outer race is stationary and the inner race vibrates, the curvature center $O_{i}$ of the inner race groove moves to point $O_{i}^{\prime}$ under the applied load. Then the deformation $\delta_{b}\left(\varphi_{j}\right)$ can be calculated by

$$
\delta_{b}\left(\varphi_{j}\right)= \begin{cases}A_{i e}^{\prime}\left(\varphi_{j}\right)-A_{i e} & \text { for } \delta_{b}\left(\varphi_{j}\right)>0 \\ 0 & \text { for } \delta_{b}\left(\varphi_{j}\right) \leqslant 0\end{cases}
$$

and

$$
\begin{aligned}
& A_{i e}^{\prime}\left(\varphi_{j}\right)=\sqrt{\left(X_{a j}\right)^{2}+\left(X_{r j}\right)^{2}} \\
& X_{a j}=A_{i e} \sin \alpha_{0}+z_{b}+R_{C} \theta_{b x} \sin \varphi_{j}-R_{C} \theta_{b y} \cos \varphi_{j} \\
& X_{r j}=A_{i e} \cos \alpha_{0}+y_{b} \sin \varphi_{j}+x_{b} \cos \varphi_{j}-r_{l}
\end{aligned}
$$

where $A_{i e}$ and $A_{i e}^{\prime}$ are the unloaded and loaded relative distances between $O_{i}$ and $O_{e}$, respectively; $r_{l}$ is the radial clearance of the bearing. Therefore, according to Hertz contact theory, the relation between the bearing force and displacement at the $j$-th rolling element can be written by

$$
F_{B j}\left(\varphi_{j}\right)=\left\{\begin{array}{lll}
\mathbf{K}_{n} \sqrt{\left(\delta_{b}\left(\varphi_{j}\right)\right)^{3}} & \text { for } & \delta_{b}\left(\varphi_{j}\right)>0 \\
0 & \text { for } & \delta_{b}\left(\varphi_{j}\right) \leqslant 0
\end{array}\right.
$$

where $\mathbf{K}_{n}$ is the Hertz contact stiffness coefficient.

The contact angle of the rolling bearing will change after loading. According to Fig. 4, the contact angle after loading is

$$
\alpha_{B j}^{\prime}\left(\varphi_{j}\right)=\arctan \frac{X_{a j}}{X_{r j}}
$$

The nonlinear bearing force $\mathbf{F}_{b}(t)$ for $N$ rolling elements can be represented by

$$
\begin{array}{ll}
F_{b x}=\sum_{j=1}^{N} F_{B j}\left(\varphi_{j}\right) \cos \alpha_{B j}^{\prime} \cos \varphi_{j} \quad & F_{b y}=\sum_{j=1}^{N} F_{B j}\left(\varphi_{j}\right) \cos \alpha_{B j}^{\prime} \sin \varphi_{j} \\
F_{b z}=\sum_{j=1}^{N} F_{B j}\left(\varphi_{j}\right) \sin \alpha_{B j}^{\prime} & \\
\mathbf{M}_{b x}=\sum_{j=1}^{N} R_{C} F_{B j}\left(\varphi_{j}\right) \sin \alpha_{B j}^{\prime} \sin \varphi & \mathbf{M}_{b y}=-\sum_{j=1}^{N} R_{C} F_{B j}\left(\varphi_{j}\right) \sin \alpha_{B j}^{\prime} \cos \varphi
\end{array}
$$

\section{Dynamic characteristic analysis}

The Runge-Kutta method is applied for solving the coupled model. The structural parameters and loading conditions of each element of the system are shown in Tables 1-4.

By solving the model, the dynamic transmission error and the mesh force at different speeds are obtained under $120 \mathrm{Nm}$ torque load conditions as shown in Figs. 5a and 5b. Figure 5a shows that the dynamic transmission error is prone to peak responses when the input speed is roughly $3360,5000,6720$ and $11990 \mathrm{r} / \mathrm{min}$, and vibration is severe at $3360 \mathrm{r} / \mathrm{min}$. From Fig. $5 \mathrm{~b}$, as the speed increases from $10 \mathrm{r} / \mathrm{min}$ to $3355 \mathrm{r} / \mathrm{min}$, the mesh force fluctuation value first decreases and then increases rapidly. Due to the weakening effect of the flexible shaft on high-speed vibration, the obvious response peaks are roughly distributed at input speeds $3355 \mathrm{r} / \mathrm{min}, 5000 \mathrm{r} / \mathrm{min}$, $6715 \mathrm{r} / \mathrm{min}$ and $11980 \mathrm{r} / \mathrm{min}$ with little difference in the response amplitudes. Figure 6 shows the dynamic bearing force for the left bearing on the driving shaft at different rotating speeds. 
Table 1. Basic parameters of the system load condition

\begin{tabular}{|l|c|c|}
\hline & Torque $[\mathrm{Nm}]$ & Speed [rpm] \\
\hline Normal load & 120 & 4400 \\
\hline Peak load & 215 & 3754 \\
\hline Peak speed & 81 & 9000 \\
\hline
\end{tabular}

Table 2. Gear geometric parameters

\begin{tabular}{|l|c|c|}
\hline \multicolumn{1}{|c|}{ Parameters } & Driving gear & Driven gear \\
\hline \hline Number of teeth & 19 & 87 \\
\hline Tooth width [mm] & 24 & 28 \\
\hline Normal modulus [mm] & \multicolumn{2}{|c|}{2} \\
\hline Pressure angle [ $\left.^{\circ}\right]$ & \multicolumn{2}{|c|}{14.5} \\
\hline Helix angle [ $\left.{ }^{\circ}\right]$ & 30 & -30 \\
\hline Mass [kg] & 0.09 & 1.616 \\
\hline Moment of inertia $I_{x}, I_{y}\left[\mathrm{~kg} \mathrm{~m}^{2}\right]$ & $2.555 \cdot 10^{-5}$ & $7.26 \cdot 10^{-2}$ \\
\hline Moment of inertia $I_{z}\left[\mathrm{~kg} \mathrm{~m}^{2}\right]$ & $4.017 \cdot 10^{-5}$ & $1.437 \cdot 10^{-1}$ \\
\hline
\end{tabular}

Table 3. Geometric parameters of each shaft element

\begin{tabular}{|c|c|c|c|c|}
\hline & Shaft element & $\begin{array}{c}\text { Outer diameter } \\
{[\mathrm{mm}]}\end{array}$ & $\begin{array}{c}\text { Inner diameter } \\
{[\mathrm{mm}]}\end{array}$ & $\begin{array}{c}\text { Length } \\
{[\mathrm{mm}]}\end{array}$ \\
\hline \hline \multirow{4}{*}{$\begin{array}{c}\text { Driving } \\
\text { shaft }\end{array}$} & $L_{1}$ & 30 & 12 & 12 \\
\cline { 2 - 5 } & $L_{2}$ & 38.9 & 12 & 68 \\
\cline { 2 - 5 } & $L_{3}$ & 30 & 12 & 64 \\
\cline { 2 - 5 } & $L_{4}$ & 30 & 10 & 30 \\
\hline \multirow{4}{*}{$\begin{array}{c}\text { Driven } \\
\text { shaft }\end{array}$} & $L_{5}$ & 25 & 4 & 33 \\
\cline { 2 - 5 } & $L_{6}$ & 50 & 18 & 12.7 \\
\cline { 2 - 5 } & $L_{7}$ & 52.3 & 18 & 38.7 \\
\cline { 2 - 5 } & $L_{8}$ & 252.3 & 18 & 33.7 \\
\cline { 2 - 5 } & $L_{9}$ & 50 & 18 & 19.9 \\
\hline
\end{tabular}

Table 4. Basic parameters of bearing SKF6306 and SKF210

\begin{tabular}{|l|c|c|}
\hline \multicolumn{1}{|c|}{ Type } & SKF6306 & SKF210 \\
\hline \hline Inner race curvature center radius $[\mathrm{mm}]$ & 26.2 & 35.2 \\
\hline Radial clearance $[\mu \mathrm{m}]$ & 12.5 & 14.5 \\
\hline Number of elements & 8 & 16 \\
\hline Element diameter $[\mathrm{mm}]$ & 12.303 & 12 \\
\hline $\begin{array}{l}\text { Relative distance between inner and outer } \\
\text { race groove curvature centers }[\mathrm{mm}]\end{array}$ & 0.4921 & 0.48 \\
\hline Mass $[\mathrm{kg}]$ & 0.2125 & 0.3422 \\
\hline Moment of inertia $I_{b x}, I_{b y}\left[\mathrm{~kg} \mathrm{~m}{ }^{2}\right]$ & $7.1825 \cdot 10^{-5}$ & $2.0960 \cdot 10^{-4}$ \\
\hline Moment of inertia $I_{z}\left[\mathrm{~kg} \mathrm{~m}^{2}\right]$ & $1.4365 \cdot 10^{-4}$ & $4.1920 \cdot 10^{-4}$ \\
\hline
\end{tabular}

As seen in Fig. 6, the bearing force fluctuation in the direction $X, Y, \theta_{x}, \theta_{y}$ gradually increases and reaches its maximum peak at $7925 \mathrm{r} / \mathrm{min}$. Moreover, at the same speed, the dynamic bearing forces in the $Y$ and $\theta_{x}$ directions fluctuate more obviously than the response in the $X$ and $\theta_{y}$ directions. Figure 7 shows the displacement responses of nodes 1 and 6 located on left and right 
(a)

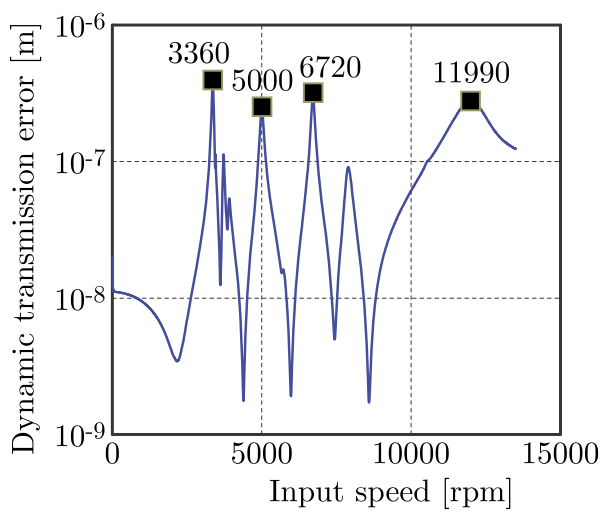

(b)

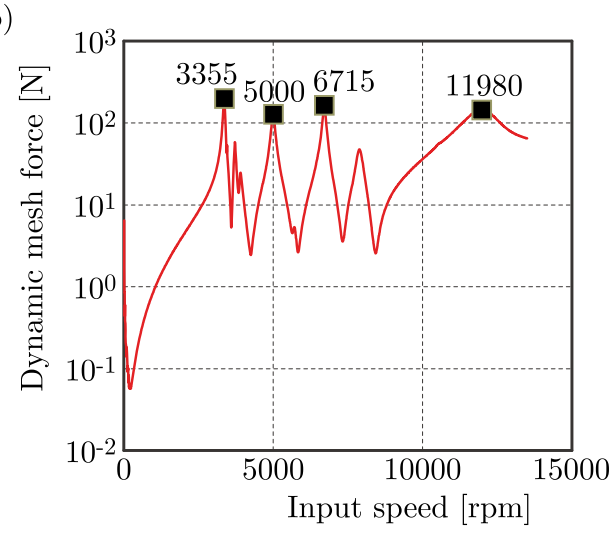

Fig. 5. (a) Dynamic transmission error, (b) dynamic mesh force

(a)

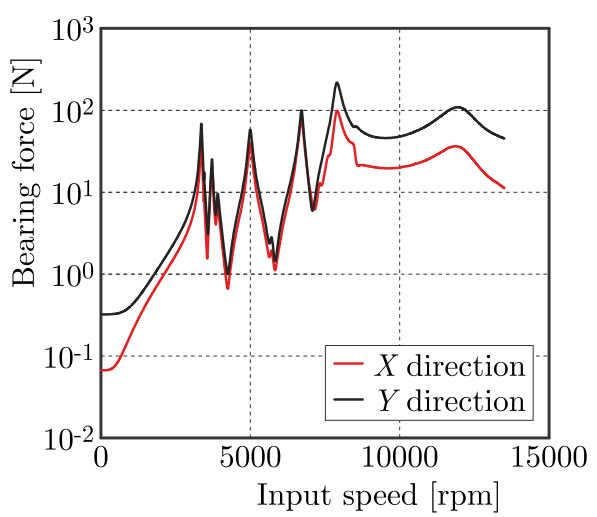

(b)

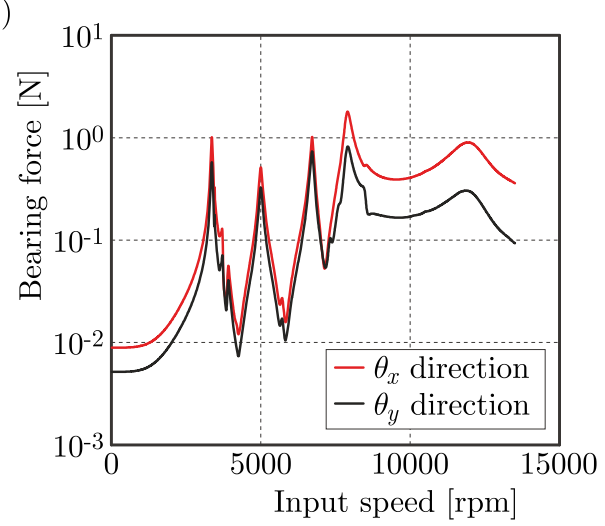

Fig. 6. Bearing force of the driving shaft left bearing with different speeds: (a) in the $X, Y$ direction, (b) in the $\theta_{x}, \theta_{y}$ direction

(a)

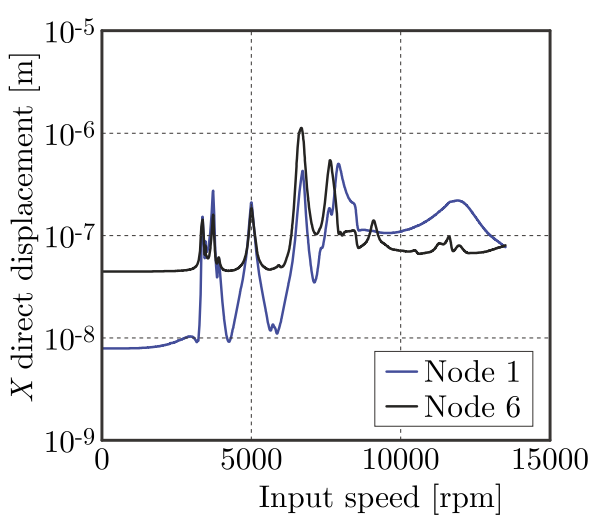

(b)

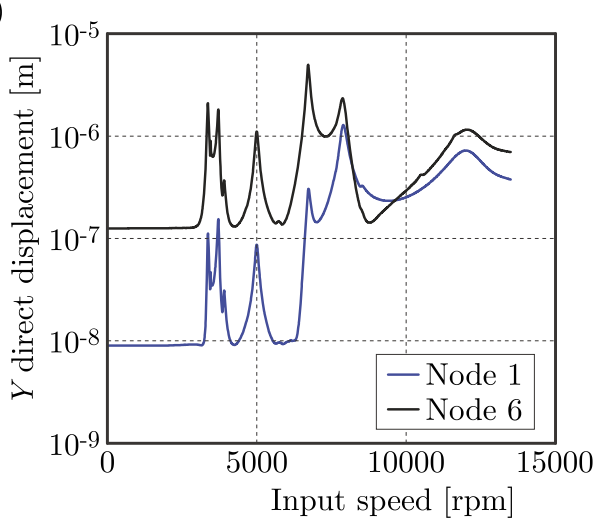

Fig. 7. The displacement response of the driving shaft left and right ends (namely nodes 1,6 ):

(a) $X$ displacement of node 1 and 6, (b) $Y$ displacement of node 1 and 6

ends of the driving shaft. From Fig. 7, the responses at the right end are significantly larger than the responses at the left end, because the torque input is applied to the right end of the driving shaft.

\subsection{Load impact on dynamics}

Figure 8 shows the influence of torque load on the dynamic bearing force of the left bearing located on the driving shaft. 
(a)

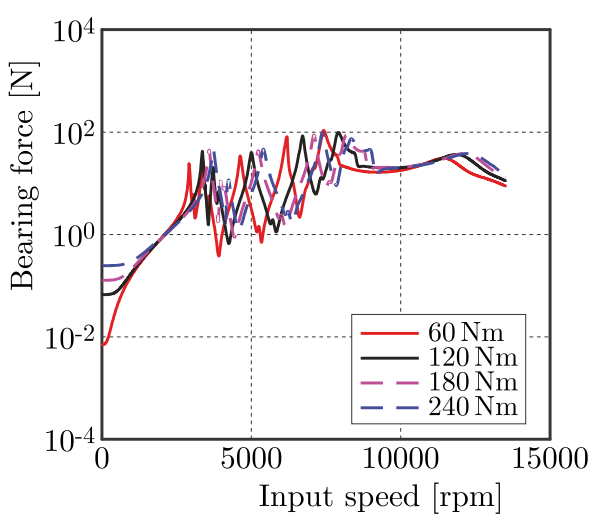

(c)

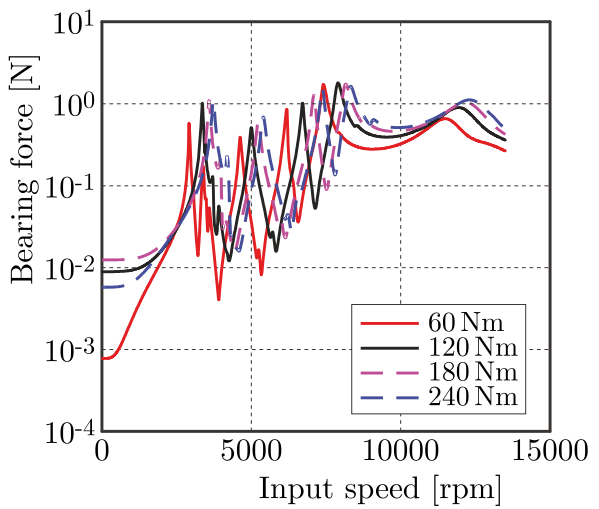

(b)

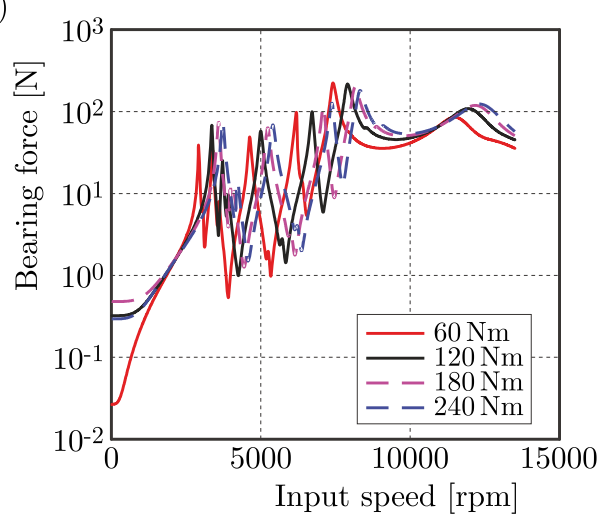

(d)

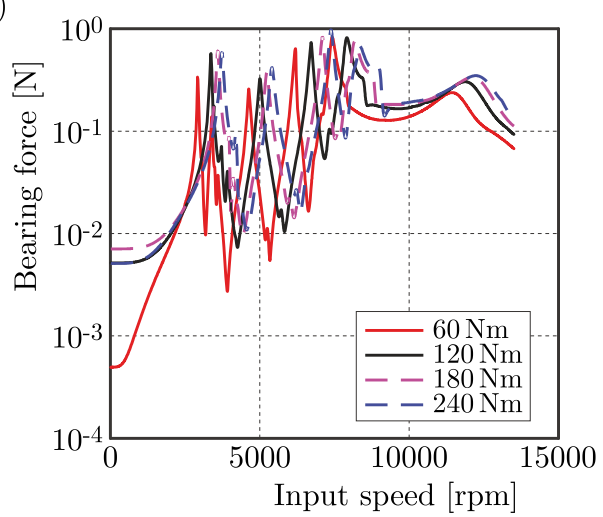

Fig. 8. Influence of torque load on the bearing force: (a) $X$ bearing force, (b) $Y$ bearing force, (c) $\theta_{x}$ bearing force, (d) $\theta_{y}$ bearing force

From Fig. 8 one can see that the main response peak of bearing force increases and the excitation frequency corresponding to the main response peak also increases obviously with the increase of load. The main reason for the increase of the response amplitude is that mesh stiffness and transmission error are increased due to torque load increment, as shown in Table 5.

Table 5. Meshing stiffness and transmission error for different load conditions

\begin{tabular}{|c|c|c|c|c|}
\hline $\begin{array}{c}\text { Torque } \\
{[\mathrm{Nm}]}\end{array}$ & $\begin{array}{c}\text { Mesh stiffness } \\
\text { mean }[\mathrm{N} / \mathrm{m}]\end{array}$ & $\begin{array}{c}\text { Mesh stiffness } \\
\text { amplitude }[\mathrm{N} / \mathrm{m}]\end{array}$ & $\begin{array}{c}\text { Transmission error } \\
\text { amplitude }[\mathrm{m}]\end{array}$ & $\begin{array}{c}\text { Initial phase } \\
\text { angle }\left[{ }^{\circ}\right]\end{array}$ \\
\hline \hline 60 & $4.817 \cdot 10^{8}$ & $6.768 \cdot 10^{5}$ & $3.27 \cdot 10^{-7}$ & -117.49 \\
\hline 120 & $5.059 \cdot 10^{8}$ & $6.077 \cdot 10^{5}$ & $3.50 \cdot 10^{-7}$ & -117.49 \\
\hline 180 & $5.059 \cdot 10^{8}$ & $6.077 \cdot 10^{5}$ & $3.63 \cdot 10^{-7}$ & -117.49 \\
\hline 240 & $5.059 \cdot 10^{8}$ & $6.077 \cdot 10^{5}$ & $3.75 \cdot 10^{-7}$ & -117.49 \\
\hline
\end{tabular}

\subsection{Bearing clearance impact on dynamics}

From Table 4, the bearing types on both sides of the driving shaft and the driven shaft are SKF6306 and SKF210, respectively. According to the ISO Standard, the standard radial clearance of bearing SKF6306 and SKF210 are $12.5 \mu \mathrm{m}$ and $14.5 \mu \mathrm{m}$, respectively. With a constant torque of $120 \mathrm{Nm}$ and rotating speed of $4400 \mathrm{r} / \mathrm{min}$, the impacts of different bearing clearances $6.5 \mu \mathrm{m}, 9.5 \mu \mathrm{m}, 12.5 \mu \mathrm{m}, 15.5 \mu \mathrm{m}$ and $18.5 \mu \mathrm{m}$ for the driving shaft on the dynamic mesh force are shown in Fig. 9. In order to maintain the quantitative relationship between the input and out- 
(a)

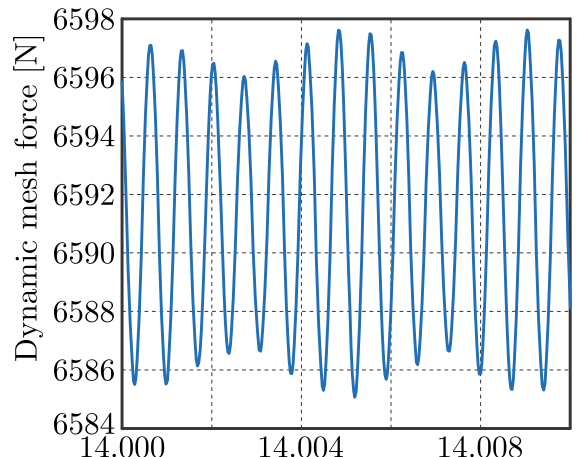

(b)

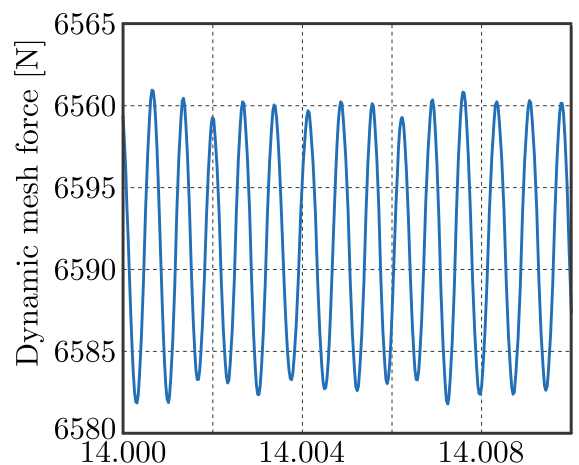

(c)

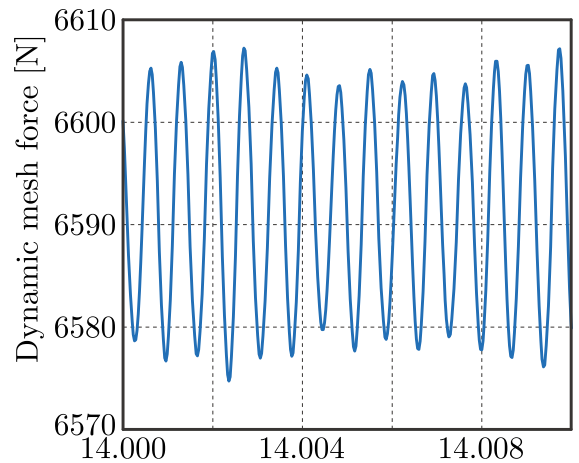

(d)

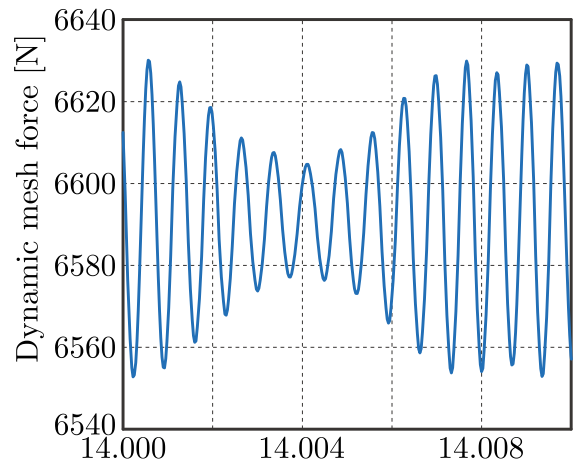

(e)

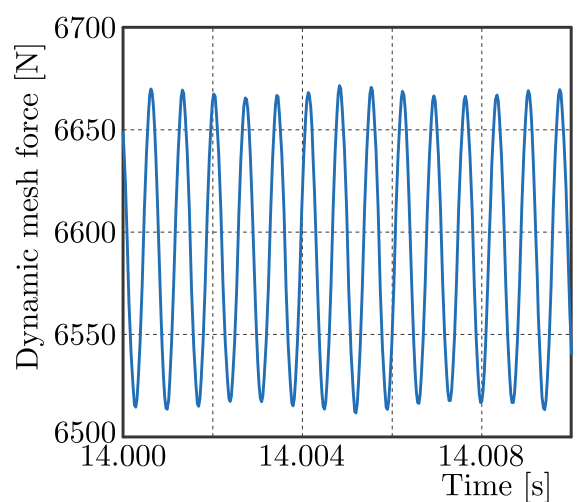

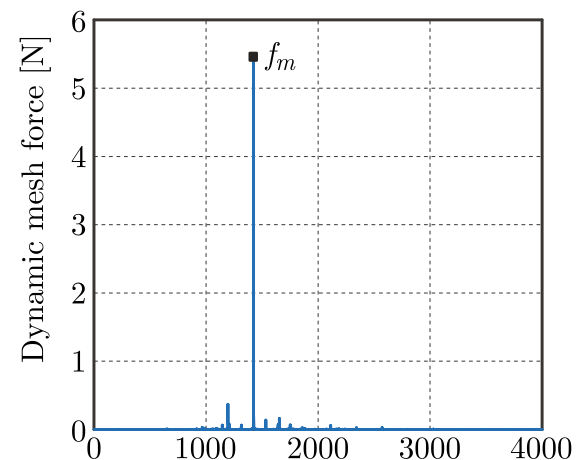
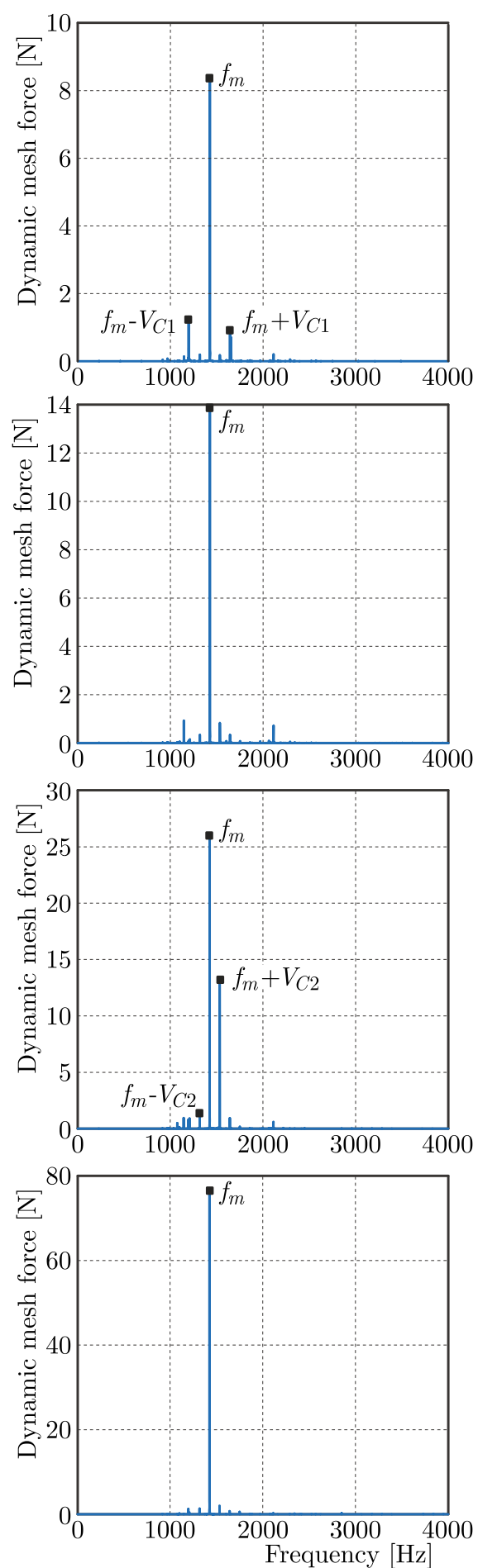

Fig. 9. Dynamic mesh forces with different bearing clearances: (a) $6.5 \mu \mathrm{m}$, (b) $9.5 \mu \mathrm{m}$, (c) $12.5 \mu \mathrm{m}$, (d) $15.5 \mu \mathrm{m}$, (e) $18.5 \mu \mathrm{m}$ 
put shaft bearing clearances, the driven shaft bearing clearances were set at $7.54 \mu \mathrm{m}, 11.02 \mu \mathrm{m}$, $14.5 \mu \mathrm{m}, 17.98 \mu \mathrm{m}$ and $21.46 \mu \mathrm{m}$. Figure 9 shows dynamic mesh forces with different bearing clearances at $4400 \mathrm{rpm}$. For the speed $4400 \mathrm{rpm}$, the gear mesh frequency is $1425 \mathrm{~Hz}$, the driving shaft bearing passing frequency $V_{C 1}$ is $229 \mathrm{~Hz}$ and the driven shaft bearing passing frequency $V_{C 2}$ is $108 \mathrm{~Hz}$.

As Fig. 9 shows, the dominant peak frequency of the dynamic mesh force is the gear mesh frequency $f_{m}$, and its amplitude increases significantly as the radial clearance increases. Secondly, when the radial clearance is $9.5 \mu \mathrm{m}$, the dynamic mesh force shows side frequencies $1196 \mathrm{~Hz}$ $\left(f_{m}-V_{C 1}\right)$ and $1654 \mathrm{~Hz}\left(f_{m}+V_{C 1}\right)$. When the clearance is $15.5 \mu \mathrm{m}$, the dynamic mesh force shows side frequencies $1317 \mathrm{~Hz}\left(f_{m}-V_{C 2}\right)$ and $1533 \mathrm{~Hz}\left(f_{m}+V_{C 2}\right)$.

With a constant torque of $120 \mathrm{Nm}$, the influence of bearing clearance on the dynamic mesh force is further analyzed. As Fig. 10 shows, when the speed is less than $3600 \mathrm{r} / \mathrm{min}$, the radial clearance has a small impact on the dynamic meshing force. However, when the speed exceeds $3600 \mathrm{r} / \mathrm{min}$, the excitation frequency corresponding to the main response peak decreases with the increase of the clearance, which is mainly due to the decrease of bearing stiffness resulted from the increase of bearing clearance.

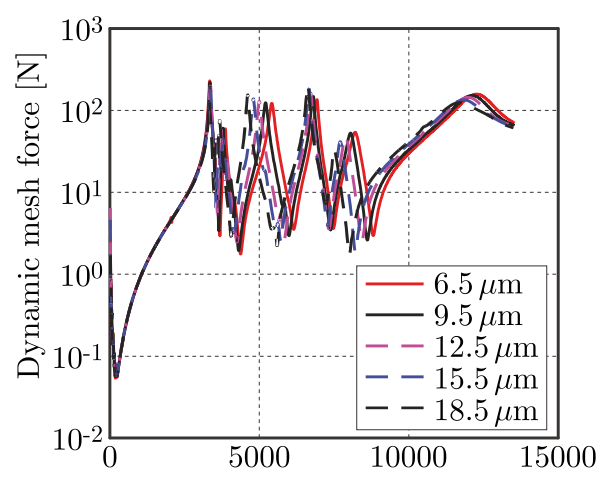

Fig. 10. Sweep frequency analysis for the dynamic mesh force

Figures 11 and 12 show the impacts of bearing clearance on the displacement in the $X$ and $Y$ directions for the left and right ends of the driving shaft. Figures 11 and 12 show that with the increase of bearing clearance, the main response peaks in the $X$ and $Y$ directions for the left and right ends of the driving shaft increase, but the increasing speed gradually decreases.

(a)

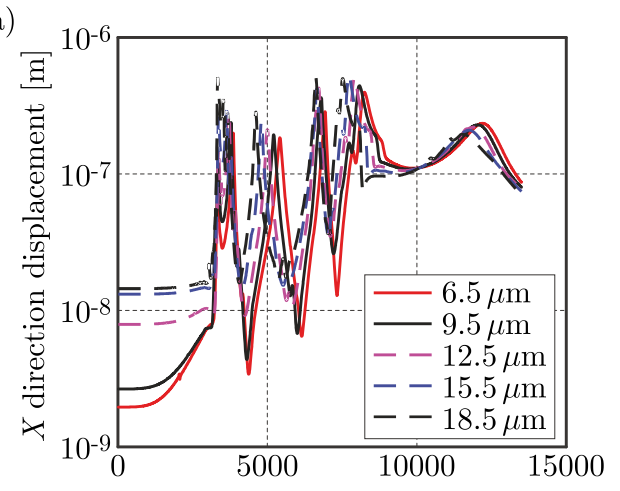

(b)

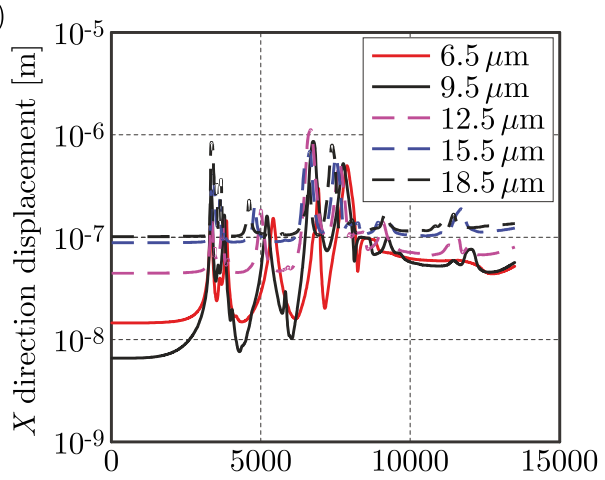

Fig. 11. $X$ displacement response of the driving shaft left (node 1 ) and right ends (node 6 ) with different clearances: (a) $X$ displacement of node 1, (b) $X$ displacement of node 6 
(a)

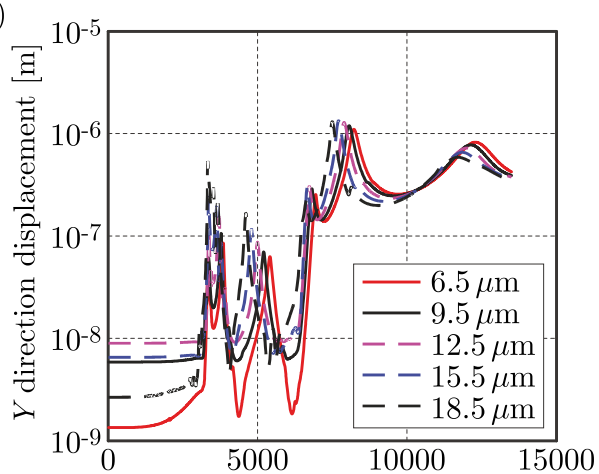

(b)

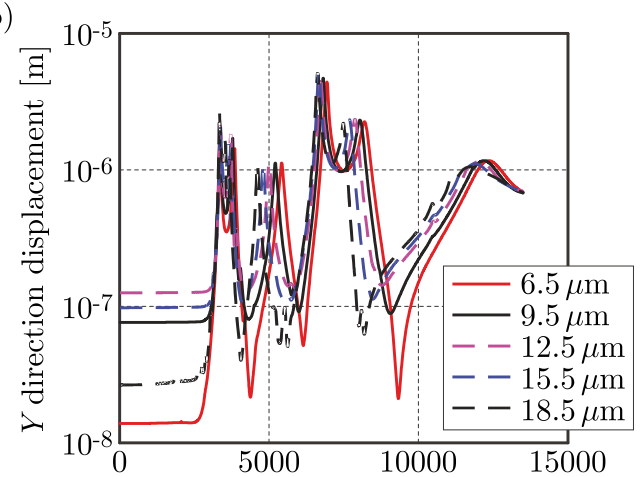

Fig. 12. $Y$ displacement response of the driving shaft left and right end with different clearances: (a) $Y$ displacement of node 1, (b) $Y$ displacement of node 6

\section{Conclusions}

- In this paper, a coupled dynamic model of a gear-shaft-bearing system is developed and the influence of rotational speeds, input torque loads and bearing clearances on the dynamic behavior is studied.

- As the rotational speed increases, the dynamic mesh force, dynamic transmission error and dynamic bearing force fluctuates. The radial displacement response between the left and right ends of the driving shaft varies greatly. The main peak response shifts to a higher frequency and its magnitude also increases with the increase of load. Under the same speed, the bearing forces along the $Y$ and $\theta_{x}$ directions fluctuate more severely than the bearing forces along the $X$ and $\theta_{y}$ directions.

- The change of bearing clearance generates side frequency components for the dynamic mesh force. As the bearing clearance increases, the amplitude of its dominant mesh frequency is obviously increased. At a low speed, the increase of bearing clearance has little effect on the dynamic mesh force. However, for moderate and high speeds, with the increase of bearing clearance, the peak response frequency of the dynamic mesh force is decreased. Therefore, when the gear transmission system is running at moderate and high speeds, it is necessary to pay attention to the influence of the clearance on the system dynamic characteristics.

\section{Acknowledgements}

The authors would like to thank the National Key Research and Development Plan of China (2019YFB2004700), National Natural Science Foundation of China (51775061), Science and Technology Major Project of Guangxi (Guike AA19182001) and Key Research and Development Project of Chongqing Technological Innovation and Application Demonstration Program(cstc2018jszx-cyzdX0056).

\section{References}

1. BAI C.Q., XU Q. Y., 2006, Dynamic model of ball bearings with internal clearance and waviness, Journal of Sound and Vibration, 294, 1-2, 23-48

2. Bonori G., Pellicano F., 2007, Non-smooth dynamics of spur gears with manufacturing errors, Journal of Sound and Vibration, 306, 1-2, 271-283

3. Chen F.F., Yu P., Zhang T., 2013, Modal analysis for the powertrain of electric vehicle by finite element method, 2nd International Conference on Industrial Design and Mechanics Power, 437, 140-145 
4. Chen G., 2008a, Nonlinear dynamics of unbalance-looseness coupling faults of rotor-ball bearing-stator coupling system, Chinese Journal of Mechanical Engineering, 44, 3, 82-88, DOI: 10.3901/JME.2008.03.082

5. Chen G., 2008b, Nonlinear dynamic study on a rotor-ball bearing system with unbalance-rubbing coupling fault, Journal of Vibration and Shock, 27, 4, 43-48, DOI: 10.13465/j.cnki.jvs.2008.04.016

6. Chen S.Y., TAng J.Y., Luo C.W., WAng Q.B., 2011, Nonlinear dynamic characteristics of geared rotor bearing systems with dynamic backlash and friction, Mechanism and Machine Theory, 46, 4, 466-478

7. Chen X.A., Miao Y.Y., Yang W., Kang H.M., 2010, Nonlinear dynamic characteristics analysis of a gear transmission system with multiple clearances based on finite element method, Journal of Vibration and Shock, 29, 2, 46-49

8. HARsha S.P., 2005, Nonlinear dynamic analysis of an unbalanced rotor supported by roller bearing, Chaos, Solitons and Fractals, 261, 47-66

9. Harsha S.P., 2006, Nonlinear dynamic analysis of a high-speed rotor supported by rolling element bearings, Journal of Sound and Vibration, 290, 1-2, 65-100

10. Kang M.R., Kahraman A., 2016, An experimental and theoretical study of the dynamic behavior of double-helical gear sets, Journal of Sound and Vibration, 350, 11-29

11. LeE A.S., HA J.W., Choi D.H., 2003, Coupled lateral and torsional vibration characteristics of a speed increasing geared rotor-bearing system, Journal of Sound and Vibration, 263, 4, 725-742

12. Li M., 2008, Non-linear dynamic behavior of rotor-bearing system trained by bevel gears, Proceedings of the Institution of Mechanical Engineers - Part C: Journal of Mechanical Engineering Science, 222, 4, 617-627

13. LiEw H.V., LiM T.C., 2005, Analysis of time-varying rolling element bearing characteristics, Journal of Sound and Vibration, 283, 3-5, 1163-1179

14. Lim T.C., Singh R., 1990, Vibration transmission through rolling element bearings - Part I: Bearing stiffness formulation, Journal of Sound and Vibration, 139, 2, 179-199

15. Liu S.Y., Song C.S., Zhu C.C., Liang C.C., Yang X.Y., 2019, Investigation on the influence of work holding equipment errors on contact characteristics of face-hobbed hypoid gear, Mechanism and Machine Theory, 138, 95-111

16. Moradi H., Salarieh H., 2012, Analysis of nonlinear oscillations in spur gear pairs with approximated modelling of backlash nonlinearity, Mechanism and Machine Theory, 51, 14-31

17. Qin Y., Zou J.Q., TAng B.P., Wang Y., Chen H.Z., 2019, Transient feature extraction by the improved orthogonal matching pursuit an K-SVD algorithm with adaptive transient dictionary, IEEE Transactions on Industrial Informatics, DOI: 10.1109/TII.2019.2909305

18. Sheng D.P., Zhu R.P., Feng X., Jin G.H., 2014, Bifurcation characteristics of bending-torsional coupled gear nonlinear vibration with multi-clearance, Journal of Vibration and Shock, 33, 19, 116122, DOI: $10.13465 /$ j.cnki.jvs.2014.19.020

19. Sopanen J., Mikkola A., 2003, Dynamic model of a deep-groove ball bearing including localized and distributed defects. Part 2: Implementation and results, Proceedings of the Institution of Mechanical Engineers - Part K: Journal of Multi-Body Dynamics, 217, 3, 213-223

20. Stringer D.B., 2008, Geared rotor dynamic methodologies for advancing prognostic in rotarywing transmission systems, Ph.D. dissertation, Virginia University, Virginia, America

21. Wang W., LiU H.J., Zhu C.C., Du X.S., TANG J.Y., 2019, Effect of the residual stress on contact fatigue of a wind turbine carburized gear with multiaxial fatigue criteria, International Journal of Mechanical Sciences, 151, 263-273

22. Wang Y.W., Yang J.Y., Guo D., Lim T.C., 2016, Vibration and sound radiation analysis of the final drive assembly considering the gear-shaft coupling dynamics, Proceedings of the Institution of Mechanical Engineers - Part C: Journal of Mechanical Engineering Science, 230, 7-8, 1258-1275 
23. XU L.X., Li Y.G., 2012, An approach for calculating the dynamic load of deep groove ball bearing joints in planar multibody systems, Nonlinear Dynamics, 70, 3, 2145-2161

24. Xu L.X., Yang Y.H., Li Y.G., Li C.N., Wang S.Y., 2012, Modeling and analysis of planar multibody systems containing deep groove ball bearing with clearance, Mechanism and Machine Theory, 56, 69-88

25. Yu P., Zhang T., Leng Y., Guo R., 2015, Vibration characteristics analysis and improvement of differential/reducer of electric vehicle, Journal of Vibration and Shock, 34, 7, 85-92, DOI: 10.13465/j.cnki.jvs.2015.07.014

26. Zhang A.Q., Wei J., Shi L., Qin D.T., Lim T.C., 2019, Modeling and dynamic response of parallel shaft gear transmission in non-inertial system, Nonlinear Dynamics, 98, 2, 997-1017

27. ZHou J.X., LiU G., Wu L.Y., 2013, Effect of operating conditions on vibration and noise radiation of a gear reducer, Journal of Vibration and Shock, 32, 8, 193-198

Manuscript received September 30, 2019; accepted for print December 18, 2019 